\section{Conservation science - a creative tension}

\author{
Gary K. Meffe
}

\author{
Conservation: The careful utilization of a \\ natural resource in order to prevent \\ depletion. \\ Science: Systematic knowledge of the \\ physical or material world gained through \\ observation and experimentation.
}

Conservation science is born of an inherent conflict. On one hand it is based in science, an objective, value-free search for truth that leads to general laws, with no a priori desire for particular outcomes. On the other hand it is clearly driven by value-laden goals related to making the human-nature relationship an enduring one. In contrast to an objective science, particular outcomes - such as preservation of biodiversity and protection or restoration of functioning ecosystems - are clearly pursued in conservation. The result is a sometimes uncomfortable merging of two human endeavours - one objective and one value-laden that are inherently antagonistic and can result in tension. To make this tension creative, rather than destructive, we need to understand how both components are necessary and synergistic in forming a complete conservation science.

In the USA we have been wrestling with this issue for several years, and debate has ensued as to the proper roles for conservation scientists in society. Do we retain strict scientific objectivity, conduct our studies, and let the chips fall where they may? That strategy leaves us free of criticism and above reproach; we cannot be faulted for political leanings or bias in our work, which then may carry greater objectivity, even though it may have little influence on society. Or, do we participate more fully in a democratic society through our work, and promote an agenda that we believe to be critical to the future welfare of the planet? Do we, in fact, have an obligation, as a segment of society with specialized knowledge, to promote an agenda based on our science and the collective information we produce? If we do, does that compromise our scientific objectivity?

This debate has manifested itself in several ways. At the 1995 annual meeting of the Society for Conservation Biology an evening session was held to discuss these points. Somewhat surprising to me was an overwhelming sentiment for what I might call 'controlled activism': careful but deliberate use of our science to actively promote conservation and influence public policy. A report from a special committee of the society will soon be released that will deal with this issue, and a series of opinion papers in a recent issue of the journal addressed the question of activism by conservation scientists. This summer I participated in a panel discussion/workshop at the annual meeting of the American Society of Ichthyologists and Herpetologists that addressed the role of scientists in conservation. In an overflowing room charged with great excitement, a strong consensus was reached by this traditional and conservative scientific society that scientists very much need to be involved in public policy issues and conservation agenda promotion. Throughout many segments of American science, a consensus seems to be emerging that our role is more than production of 'pure' science, that we indeed have an obligation to society to promote informed environmental policy based on our work, and pursue a more lasting and less destructive relationship with the earth.

But such a conclusion remains troublesome to many. Does science not stand apart from other human pursuits in its objectivity? Will we not compromise the field in order to make social gains? And do we have a right to enter the policy fray, armed with our specialized knowledge, when those in other aspects of science 'obey the rules' and quietly toil away, free from controversy? There is another way to envision this dilemma that may help address these queries, and provide licence to do what we feel is socially responsible: yes, we are scientists with responsibilities to the field, but we are also citizens with responsibilities to society. This dual role of citizen-scientist, I feel, both permits and demands that we use our individual and collective knowledge and 
talents for the betterment of all biodiversity, including humanity. And the most effective way to do this is to actively ensure that our knowledge base is consulted and used in the development of informed public policy. Policy is where the best knowledge of the day should be brought to bear to solve problems common to a society. To not bring that information fully to light is, in my estimation, negligent.

Is there a way to retain scientific objectivity while admitting to and even embracing value systems of conservation? I most certainly believe there is. Science always should be conducted in an objective, value-free way; there should never be a hint of bias in how we do the science. However, what we choose to do can very much be motivated by values, as is how we choose to use or apply the results; this is where we can and should become activists in conservation. For example, one could choose to revise the taxonomy of a group of tropical beetles because that is what interests the individual, and that is where their talents lie. Perhaps, ultimately, that information could prove useful in a conservation context if a policy maker happens to encounter it and understand its value. Or, that same scientist could purposely set out to study a fauna - perhaps those same beetles - because there is an urgent need to define the group to develop objective, scientific arguments for its conservation in the light of imminent development in the area. And the process can be taken a step further by promoting that information to decision makers, in effect forcing them to take under consideration this new knowledge base and arguing for its relevance. It is the same type of science in both cases, but driven by different intentions, plus an active pursuit of its application.

Is the latter somehow tainted because of the motivation behind it? I believe it is enhanced because it combines good, objective science with an immediate conservation need based on a well-developed value system; it takes the science to a new level. However, if the science becomes compromised because of the value system it is fraud. Values can affect what we do in science, and how we choose to apply it, but not how the science is conducted.

Gunderson et al. (1995) proposed five major roles that scientists may play in society in general and policy making in particular.

1 Reductionist 'keepers of the faith'. We reinforce existing paradigms of management by increasing the precision and efficiency of data collection rather than testing questions that may overturn policy.

2 Repositories of understanding. We accumulate knowledge that may be called upon for policy formation; we have the various pieces if needed.

3 Announcers of crises. We announce failures of existing policy, such as ozone holes, global warming, or fisheries collapses.

4 Wise, respected integrators. We can put the various pieces together, if asked, to reform policy.

5 Generators of new types of policy. We use our knowledge and experience to actively develop new, science-based policy with the intention of better, and adaptive, management.

Many scientists carry out the first three roles quite well, some become involved in the fourth level, but few dare to enter the fifth. This is what is critically needed and what many of us need to learn to do. We must remember a critical truism of the political arena: public policy will be made with or without the influence of good science and the use of good information (Meffe and Viederman, 1995). It is up to us to intentionally make our science relevant to, and understandable by, policy makers. Conservation is not an armchair science - we must put into action what we know, or we will come to regret it.

Thomas Lovejoy (1995) summarized the tasks we face: 'The real challenge is how we as biologists can create that sense of urgency about biological diversity, climate change, and human population growth. These are problems that grow by increments and that may not seem of particularly great consequence, but which in aggregate are disastrous. No group is in a better position than are biologists to make the case and make it eloquently. It is likely to be hard, and maybe even impossible, to make significant progress unless we biologists enter the fray with greater energy and passion than we have done so far.'

Lovejoy went on to claim that 'now is 
biology's moment in history'. We can discuss ad nauseum whether we should dirty our hands (but then of course it will be too late), or we can devote ourselves now, 'in our moment in history', to the greatest problems humanity has ever faced. And in that sense, we are a privileged generation: I believe we have obligations to the public interest, to science, and to ourselves to convert our scientific knowledge base to sound and informed public policy. Conservation science demands that we act well, act now, and use the inherent tensions in a creative manner. A complete conservation science demands nothing less.

\section{References}

Gunderson, L.H., Light, S.S. and Holling, C.S. 1995. Lessons from the Everglades. Bioscience Supplement, 66-73.

Lovejoy, T.E. 1995. Will expectedly the top blow off? BioScience Supplement, 3-6.

Meffe, G.K. and Viederman, S. 1995. Combining science and policy in conservation biology. Wildlife Society Bulletin, 23, 327-332.

Gary Meffe is a Professor at the University of Georgia and the Savannah River Ecology Laboratory, and is senior author of Principles of Conservation Biology (Sinauer Associates, 1994).

\section{NEWS AND VIEWS}

\section{Realistic 'game laws'}

Spinage (1996), in discussing 'The rule of law and African game - a review of some recent trends and concerns', confuses the need for legislation with what constitutes effective law. He incorrectly implies that Child (1995a) and Clark and Bell (1984; who have each drafted legislation to conserve wildlife for several countries in Africa and the Middle East), are among those who advocate doing away with law to regulate the management and use of wildlife. In so doing he offers a spirited, if subjective, defence of colonial-type legislation that fails to accept that such legislation has contributed little if anything to the well-being of the macrofauna in the 96 per cent of Africa outside protected areas. In reality, the centrally directed protectionist philosophies contained in colonial-type game laws failed outside protected areas in Africa (and elsewhere) as dismally as centrally controlled economies failed in Eastern Europe (and elsewhere), and this was for similar reasons (Child, 1995b). A fresh approach is essential.

Clive Spinage finds the success of the Zimbabwean model of wildlife management uncomfortable and suggests that it has been in operation for too short a period to allow a reliable evaluation of its merit. In fact, the Zimbabwean approach was introduced progressively and with growing confidence from 1961. By 1970 we were confident of its merit and it became enshrined in law in 1975. Success stems from recognition of the role of landholders in deciding the fate of wild resources, and acceptance that their decisions are driven by social and economic considerations. This does not negate the need for law, but requires that the legislation accept these realities if it is to realize its intent.

Although the conservation of renewable resources deals with biological phenomena, it is the socio-economic process by which societies are attempting to address growing resource scarcities. Success depends on conforming with basic economic principles within the broad parameters laid down by the immutable laws of nature. Regulating the use of a resource is socially inefficient while a resource is still plentiful, but becomes essential once the resource reaches the threshold of scarcity at which overuse commences. Where the resource in question is one of a suite of resources contributing to local human well-being, it is important that measures taken to protect the target resource do not prejudice its capacity to compete for space with the other resources in the suite. Where people live off the land any 